\title{
'You have to find a location where you will sell, where you think you will sell most' - Exploring the numeracy skills of female microcredit clients in Nicaragua
}

\author{
SONJA BEELI-ZIMMERMANN
}

\begin{abstract}
Using Lindenskov and Wedege's (2001) working model for numeracy, semi-standardised interviews with self-employed women in Nicaragua were analysed. The analysis illustrates that the women's numeracy skills are not limited to counting and calculation skills when dealing with financial matters. The interviewees display a broad understanding of patterns and relations, and there are indications of an awareness of data and chance. While the medium of money plays an important role, the women also refer to specific products, time or people when displaying their numeracy skills. If the livelihoods of these women are to be improved and international development goals and educational commitments are to be reached and fulfilled, it is suggested that these skills that the women already possess should be investigated more systematically in order to better understand the transfer of knowledge between different contexts.
\end{abstract}

\section{Introduction}

Context is a fundamental and frequently discussed term in debates about numeracy. Context and skills constitute two core aspects of numeracy development. Two different meanings of context can be distinguished: that of location or situation, and that of problems or tasks. For this article, the situational context is foregrounded. It has been found that a person's numeracy skills depend on where they have to be displayed (see for example Lave 1988, Saxe 1991, Nunes, Schliemann and Carraher 1993) and the transfer of skills between different contexts, particularly between educational and work settings, is a much debated issue. However, as will be seen below, understanding and facilitating transfer in the other direction, namely from work to learning contexts, is equally important. As situational context also includes wider aspects such as historical and social relations, the fact that this article - unlike many others dealing with numeracy - is not based on information gathered 'in the western hemisphere and developed nations of the world' (Naresh 2008:9) needs to be mentioned.

Numeracy studies from developing countries are rare, but seem to be increasing. Lekoko and Garegae (2006), for example, describe the skills of 
women street vendors in Botswana, a target population closely related to that of this article. Naresh (2008) describes the workplace mathematics of bus conductors in India, and Gahamanyi (2010) explores mathematics use at various workplaces and educational settings in Rwanda. The data for this article were collected in 2008 in Nicaragua, with the aim of learning more about the planning skills of microcredit clients with little or no formal education. Notably, the initial motivation for the data collection was not a focus on numeracy but a concern with planning, making this article a reanalysis of the data from a numeracy perspective. This presents both advantages and disadvantages with the former being the fact that the informants were under no pressure to solve any quantitative problems or perform set tasks. Their quantitative statements can indeed be considered as having occurred spontaneously without specific prompts and are therefore an illustration of how relevant quantitative issues are in their lives. The main disadvantage is that the data are insufficient for systematic assessment, therefore limiting the nature of this article to exploration and description.

There are two main reasons for describing numeracy in non-western and non-industrialised countries: adding to a broader understanding of context in the numeracy debate, and political relevance. Education is considered to be a key ingredient for development (see for example Barton and Papen 2005, Archer and Jeng 2006). More specifically, literacy (understood in a broader sense to include numeracy) is considered to be 'the invisible ingredient in any successful strategy for eradicating poverty' (Archer and Jeng 2006:2). The international community has committed itself repeatedly to both the reduction of illiteracy (World Education Forum 2000) and poverty (United Nations 2000). These goals cannot be achieved by merely focusing on getting all children into school, there also needs to be considerably more investment in getting adults into effective literacy programs. Effective literacy programs are characterised, among others, by participatory methods that ensure their relevance to the learners' lives (Archer and Jeng 2006). A better understanding of poor people's livelihoods in general, and their literacy and numeracy use in particular, could therefore contribute to more effective educational programs and - hopefully in the long term - to achieving the international community's commitments and granting adults their right to education.

\section{Theoretical background}

The initial theoretical research framework relating to planning (Friedman and Scholnik 1997) that was used to collect the data was not considered to be adequate for a reanalysis from a numeracy perspective. At the same time, a purely skills based or autonomous numeracy model was considered to be inadequate as it negates contextual factors (Baker and Street 1994), one of the key characteristics of the available data. Finally, a 
'You have to find a location...'

working model for numeracy as an analytical tool described by Lindenskov and Wedege (2001) was found to be suitable. It has an empirical basis and 'is not seeing skills and understandings isolated' (Lindenskov and Wedege 2001:11), but together with three other dimensions. The other three dimensions are media, context and personal intentions. Media refers not only to written and oral information, but also to concrete materials, time and processes. Context is understood as situational context referring to historical, social and other relations where numeracy skills are used. And finally, the dimension of personal intentions includes conscious and unconscious conceptions. The two latter dimensions, context and personal intentions, allow for both an objective and subjective approach to numeracy. Indeed, Lindenskov and Wedege stress that contrasting contexts 'both inside and outside the system of education [... are needed in order] to see that personal intentions, media and situational contexts emerge as being equally important to skills and understanding' (Lindenskov and Wedege 2001:12).

A similar research approach is taken by Street, Baker and Tomlin (2008) who contrast home and school numeracy practices. Their conceptualisation of numeracy practices resembles Lindenskov's and Wedeges, as they also differentiate four dimensions, namely content, context, values and beliefs, and social and institutional relations. And while a detailed comparison of the two conceptualisations is beyond the scope of this paper, it is worth noting that in spite of some overlaps and similarities, there are some important differences: most notably the explicit inclusion of hierarchy and power in the dimension of social and institutional relations by Street, Baker and Tomlin. However, the concept of numeracy practices understood as an expansion of numeracy events and as such more than numerical activity, was not considered adequate for this reanalysis of the data which had not been gathered under the same theoretical perspective, particularly as no actual numeracy events were observed. Lindenskov and Wedeges' model, on the other hand, was considered to be an ideal instrument to explore the role of numeracy in the daily lives of women working in the informal sector.

\section{Study background}

Nicaragua is located in Central America and is one of the poorest countries in the region. Out of its population of 5.9 million almost half (48 percent) live in poverty (Central Intelligence Agency 2010). One important characteristic of Nicaragua's economy is the fact that a large share of its gross domestic product is generated in the informal sector; Vuletin (2008) estimates this rate to be at $65-70$ percent. Apart from the agricultural work force, home based workers and street vendors form the two largest subgroups of the informal work force (International Labour Organisation 2002). The data used for this article were collected from women who fall 
into these two subgroups. At the time of the interviews they all lived in Matagalpa, a city located $130 \mathrm{~km}$ north of the capital Managua. Matagalpa has some 130,000 inhabitants and is the centre of national coffee production with coffee being one of the country's main export goods.

Economic prosperity is a key concern in international cooperation. One instrument that has become increasingly popular is microfinance particularly microcredits. Access for poor people to such services is difficult for various reasons, among them the comparatively high transaction costs and the fact that they cannot offer traditional securities, such as a piece of land or a house. Apart from strengthening the poor's economic basis, microfinance has also been found to have an empowering effect by allowing people to move from a reactive to a more proactive mode of managing their assets (Sebstad and Cohen 2003). Access to financial services in the form of microfinance therefore not only provides poor people with the opportunity to build up their economic assets, but also addresses other dimensions of poverty such as exclusion and powerlessness.

Worldwide, numerous organisations implement an equally varied number of microfinance programs. The women interviewed for this study participated in an international program called TrickleUp which is administered by local non-governmental organisations (NGOs), namely ODESAR (a local Nicaraguan organisation working for the economic and social development of municipalities) and Aldea SOS (a branch of SOS Children's Villages International). They provide selected women with an interest-free \$US100 credit, which is paid out in two tranches of \$US50, three months apart. The women have to repay it one year later ${ }^{i}$, also within a time-frame of three months. One requirement of the program is that the money has to be used to either start or enlarge a business. Furthermore, the women participate in short workshops in which not only important information with respect to the credit is shared, but also specific skills, such as basic bookkeeping or saving strategies, are imparted. However, being affiliated with Aldea SOS means that many of the women also attend other workshops on topics such as alphabetisation, handicrafts, childcare, selfesteem or domestic violence.

\section{Data collection and analysis}

Data for this article were collected using semi-standardised interviews with 19 women, and the interviews were conducted by the author in Spanish. The interview guidelines included the following: a description of the interviewees' business, financial aspects of the business, use of the credit and the process of paying it back. Socio-economic data of the interviewees were obtained through Aldea SOS. The interviews were held in various locations such as the women's point of selling in the street or at the market, an office on the premises of Aldea SOS or at the women's 
'You have to find a location...'

homes. They lasted 30 minutes on average (minimum 18 minutes, maximum 50 minutes). In many interviews third parties were present (Aldea SOS staff or children), and some interviews were interrupted by customers. Another aspect that had an influence on the interview situation was the fact that they were conducted by a person with a faulty knowledge of Spanish and - from the women's perspective - with a very different social background.

For the analysis, the digitally recorded interviews were transcribed (in Spanish) and then analysed with MAXQDA, a program for qualitative data analysis. Following Mayring's method of qualitative content analysis (Mayring 2008) different categories were formulated. As a first step, deductive categories derived from Lindenskov and Wedege's working model were used to gain more insight into those statements considered relevant to numeracy. As a second step, inductive categories were added in order to further analyse and describe these categories. The deductive categories correspond to the four dimensions and their specific elements as described above. As most codes fell into the category of skills dimension, this will be described here in more detail. The subcodes in this category include the following: dealing with and sense of (a) quantity and numbers, (b) dimension and form, (c) patterns and relations (d), data and chance, (e) change, and (f) models (Lindenskov and Wedege 2001). While statements for all of these categories could be identified, the focus of this article is on patterns and relations. On one hand this is due to the fact that most statements were categorised in this area (almost 300), on the other hand many of the statements indicate a close relationship to other categories, namely models, and to a lesser extent data and chance, which means that these categories will also be discussed in passing. Statements that were coded as belonging to the category of patterns and relations (from now on referred to as patterns only) had to meet the following criteria: they had to identify elements, and relationships between these elements, and possess an explanatory power. Typical examples include the title of this article, and the following seasonal observation: 'In December it's better, sales are good in December, until April, but in September not'.

\section{Results}

Following Wedege's argument that 'whether or not an adult knows mathematics can only be answered after the questions such as who, where, when, what and related to what' (Wedege 1999:206) have been asked, the results are presented under these headings. In line with the priorities outlined above, the answers to 'what' will be discussed most extensively. 


\section{Who}

At the time of the interview the average age of the women was 31 years (the youngest being 21, the oldest 51, most being younger than 35 ). The 19 informants were chosen on a layered random basis by representatives of the two NGOs according to the following criteria: (1) their status in the program, i.e. half of the women had just received the first half of the credit while the other half of the group was already in the process of paying it back; (2) their educational background - of the 19 women only one had no formal schooling, nine completed six years or less, six completed between seven and ten years, and three women completed 11 years of schooling; (3) the location of the women's business - ten women had a business in a fixed location in the city (market booth or specific street corner), two worked from home and the rest were so called 'vendedoras ambulantes', meaning that they walked the streets selling their products; and (4) the type of products sold - half of the women sold food or drinks, the other half clothes, accessories or cosmetics.

In addition, two shared personal characteristics emerged from the interviews: all of the women had a strong desire to succeed and move ahead (in their words: 'salir adelante'), not least of all because they wanted to provide a safe future for their children. Furthermore, many of them stressed that they liked working for themselves and not being dependent on an employer or middle(wo)man.

\section{Where and When}

As stated before, the focus of this study lies in the work context of the interviewed women. However, in passing comments it became clear that their work life is not the only context where they make use of numeracy. Like many other women around the globe, they divide their resources between work, their families and households and in some cases evening school. Various quantitative skills and understandings can be identified in the women's statements relating to their children, their daily routines, and in references to the Nicaraguan schooling system or a location in the city. With respect to the last point it is worth mentioning, that in the city of Matagalpa the concept of blocks (of houses) is also used, and the address of many places is given by saying how many blocks to the north or south of a prominent location the place of interest is - a geometrical concept that is also familiar to many North Americans.

\section{What}

There are two important issues when starting any business: access to seed money and estimating the future sales volume. These two terms were also used as codes for subcategories, even though the line between them is 
'You have to find a location...'

not always easy to draw and as will be seen in the following paragraphs, there is a smooth transition between them.

\section{Starting a business}

Seed money - You can't make something out of nothing. There was widespread agreement among the women about this piece of general knowhow: 'In order to have a good shop, which moves, one has to have money'. Or: 'I did not work, because I had nothing to work with'. The microcredit was one possibility for the women to have access to such money. In this respect it is interesting to note their knowledge related to credits:

Because with this, ODESAR is not charging any interest. And it gives me a one-year grace period, do you understand? So I would have had to go to another institution with loads of interest.

Or:

There [financial institutions] they offer us credits, but one has to pay daily quotas or fortnightly. And sometimes, when sales are low, one does not get these quotas. And with the credit you offer we have the option to collect the money over some time, over the time given.

It is important to note that most women do consider the credit as their working capital that should not be used otherwise. They also aim at setting aside enough money during the year, in order for them to still have enough working capital after paying back the credit:

And in the first week of August it is my turn to pay. But I think by August, in these two months, that a little bit will be left, a little bit, to have a business with less worries.

Sales volume - Any vendor has to think about the generation of a certain sales volume, as his/her income directly depends on that. There are two factors the women consider in this context - the location of their business and the choice of products they offer: 'In September there is more movement because other kinds of fruit come into the market. A kind of plum, oranges. And these fruits sell better, there is more demand.' Or: 'Well, in having things that others don't have so that the customers come here.' The women's arguments always reflect the model of proportionality: 'With the credit I bought more merchandise and made more clients. ' And: 'If you have little [choice], you earn little. If you have more, then you also earn more.' 
The more they sell, the more income they have, even if there is only a small profit to be made: 'Investing in things which one sees are popular, which sell more [...] One will earn little, but will sell quickly.' Their statements also reflect their experience that there are times during the week or year when one sells more or less and that products have to be adapted: 'When school starts again I offer backpacks and school shoes. And in December I sell clothes, clothes for boys and women'. The choice of products offered is therefore an issue which is not only relevant for the starting phase, but also when running the business, as will also be seen in the next paragraph.

\section{Running a business}

Financial management - Unsurprisingly this category is the broadest and most comprehensive. This has not only to do with the topic of the interviews, but also reflects the fact that money issues are omnipresent. More specifically the following skills could be identified in the women's statements: basic accounting, namely keeping an overview of their business income and expenditures, calculating profits, using profits as savings or reinvestments, economising and managing risks and debts. All women know that profit is what remains after all expenses have been paid:

But if I have an employee, I earn nothing. But if I don't have an employee, I get to keep the super income. Yes, because in the maize business [when making tortillas] you have to buy wood, calcium hydroxide, pay for the milling[...] And if you have an employee you have to pay her.

This is also an area that indicates that many of the women do not completely separate their work and family lives, as very often expenses include food for their families or utilities such as light and water. More detailed accounting skills generally relate to written procedures, so they will be discussed under the next heading.

When calculating their profit margins, the women not only stress the importance of buying cheap merchandise:

I buy in Managua, my merchandise. I have to look for the cheapest. If I buy here, it's very expensive. Everything. So I have to go down there in order to be able to sell anything. Because if I buy here, well, what will I earn? One does not earn anything.

They are also aware of the impact of intermediary trade: 
Yes, before I bought from her. And there I earned very little, because she was the one earning. And so I bought my own merchandise and it turned out a little cheaper.

After calculating their profits, the important question is what to do with them - save or reinvest? Most women do both and in doing so many set aside a certain proportion of their profit: 'Half [of the profit] for merchandise, half I save.' This strategy of setting aside a certain amount of their profit is one the women also employ in view of paying back their credit:

We are collecting a share of what we are selling. And every now and then, not daily, but every fortnight, we see how much we have collected and go and buy dollars.

Since this strategy is also taught at workshops, it is not surprising that more than half of the women mention buying their dollars 'ittle by little' and one of them is even aware of risks of currency exchange: 'It's better little by little, because the dollar could rise.' Apart from saving money to pay back their credit or to secure their future, the other important issue in the women's financial management is reinvestment: 'I always invest in more merchandise and earn more. 'In this context most of the women stressed that the money used for their business should be invested in productive matters, rather than being spent on (from the business perspective) unproductive matters such as housing or food or

... luxuries and all that. This will bring me no good. So I say it is better to invest into the little shop and over time, I already know that there will be a little bit more left and I can buy my luxuries.

This also points to another skill used to make most of the available money, namely economising:

Because one cup of soup here in Guanuca [the local market] costs 30 pesos. So for two that'd be 60 pesos. So it's better, by cooking at home we save.

While saving, reinvesting and economising skills are mentioned by all women, only a few use risk and debt management skills. One woman 
who is selling three different brands of cosmetics targeting wealthier buyers uses two interesting strategies to secure her income:

They have to give me half the money, when I go. When I bring the product, they have to pay me the rest of the money. And if they do not pay the rest, I do not give them the product.

She even has a specific strategy for the acquisition of new customers:

If I do not know this person, then the one who has to vouch for her is you, because I do not know this person, so who will pay for that perfume or that Eau de Cologne? Nobody, so you are the one who has to vouch for it.

A less refined way of managing debts is used by some other women who keep lists of people to whom they have given credit: 'Yes, in a booklet I keep taking notes: XY owes me that much.' In doing so they remarked on different benefits of such lists, that they ease the load on their working memory and that the people in question cannot challenge the fact that they owe money. Furthermore, some women mentioned managing risks relating to their private lives, namely providing for their children:

Because I don't know if God will give me many more years to live, I don't know. But, what I'm looking for is an improvement for our home, for my children. If tomorrow I have to go or something happens to me, that they can stay in their house with their things, right?

Growth - To not only have a well-functioning but rather a growing business which provides a stable income is the aim of all women:

My dreams are to enlarge the shop to have a source of life. Well above all for that. Not so much to enrich myself, but rather to have a way of living decently.

In this context the right - and wide - choice of products is considered to be an important precondition of growth:

To put up a shop one has to keep up to date with what sells best. And even if you earn little, this money will keep coming 
'You have to find a location...'

back and coming back, right? So the money will keep coming,

the profits, and that one will invest again.

Reinvesting their money is a key business strategy identified by many women - which is not surprising, as it is also one imparted at the workshops.

Looking at these identified patterns it can be said that most of them are based on the mathematical skills of addition and subtraction as well as proportionality. All of these skills have already been identified as central to numeracy, for example, Nunes and her colleagues argued that 'the concept of proportionality does not have to be taught. It can develop on the basis of everyday experience' (Nunes, Schliemann and Carraher 1993:126). Relating these skills to the women's personal intention, it can be seen that many of them are used to evaluating decision making processes: where and what to buy or where and for how much to sell. It is worth noting that almost all of the above described skills and understandings refer to orally communicated knowledge.

\section{Related to what}

There are, however, a number of women who do basic bookkeeping:

Well, I wrote down what I bought. I've always written down what I bought. And, this, I write this down, always, what I sell in a day.

Those who do so, find it useful:

Because this helps, so that I control my expenses. [...] It helps me to plan and know on which days I earn.'

Or:

For example in these things, at the end of the week we take stock to see how much we have spent, how much money we have and how much we will buy.

Such statements indicate a more systematic manner of looking at sales and can be classified as a sense of data and chance. They can also be seen as an indication of a close relationship between the medium in which information is available (in this case written information) and the related skills since it is rather difficult to systematically deal with data and chance based on oral information only. In this sense, Lekoko and Garegae (2006) amongst many others recommend that basic bookkeeping skills are taught to street vendors. However, there are indications from the interviewed women 
that teaching particular skills without taking into account the learners' previous experiences is not always successful:

But in the workshop we haven't learned it like this. [...] You know, in the workshop we made a frame like, like this [draws while talking] with a line here [...] And in this block here we put the quantity, mmh, the price. No, it seems it was here [...] It's really nice what is in the booklet. What is happening now is that I don't remember well, how, how we put it.

Numeracy skills are clearly not only related to a particular medium but also the learners' previous experiences. Furthermore, there were a number of women who spoke in a somewhat distant manner about keeping books ('They have told us to do it.') and a few of the group who had just received the first tranche of their credit had not started keeping records for various reasons, but often promised they would start soon. Such statements can be seen as indications that the imparted skills might not be considered useful or do not integrate into the women's knowledge and are therefore not applied - by no means a new insight! In their analysis of successful literacy programs, Archer and Jeng identified participatory methods which should 'ensure active engagement of learners and relevance to their lives' (Archer and Jeng 2006:43) as one of twelve benchmarks which characterise successful adult literacy programs. They also point out that with respect to this benchmark there is a gap between rhetoric and practice.

To sum up the findings related to the various skills and understandings of the interviewed street vendors, the following can be said: the women show a number of skills relating to, and a broad understanding of patterns, in addition to dealing with and having a sense of quantity and numbers as well as models. These often relate to their work context - even though sometimes the line between work and family life cannot be drawn clearly - and are used in decision making processes, mainly when dealing with money: where and what to buy or where and for how much to sell. While most of these skills are based on oral information and communication, there are some women who keep books and particularly in this context dealing with, and having a sense of data, was also observed. The use of the two remaining categories (dimension and form, and change) of Lindenskov's and Wedege's (2001) working model of numeracy have been identified as marginal with only a few statements being coded in these two categories. However, this is attributed to the method with which the data were gathered (namely not systematically with the working model as a theoretical framework). 
'You have to find a location...'

\section{Conclusion}

The previous section has shown that street vendors working in the informal sector not only use quantities and numbers or basic mathematical skills such as addition in their work, they also make extensive use of a variety of patterns, and there are indications of them dealing with data and chance. While this assessment remains at the level of description with a focus on Lindenskov's and Wedege's (2001) dimension of skills and understanding, it seems worth exploring the identified skills in a more systematic manner by comparing and contrasting them in different situations. Contrasting educational and work settings in countries of the South as has been done by other authors (see for example, Nunes, Schliemann and Carraher 1993, Saxe 1991), seems to be of interest also in this case, where the educational setting is an informal workshop rather than a formal school setting. There are indications, however, that also in this specific setting the often demanded relevance for the learners' lives is not given, and the transfer of imparted knowledge is not happening. In view of the richness of the women's skills, the link between their (oral) knowledge as displayed in a work context and other forms of knowledge in other contexts needs to be better understood before it can be improved. Such an improvement of the women's skills is a prerequisite for both their personal as well as Nicaragua's development. Looking towards a further study, a combination of the two mentioned conceptualisations of numeracy described by Lindenskov and Wedege (2001) and, Street, Baker and Tomlin (2008) might prove fruitful, as it would also addresses issues of power, which are key in a development context.

\section{References}

Archer, D and Jeng, Y (2006) Writing the Wrongs: International benchmarks on adult literacy, retrieved Dec 272010 from: http://www.aspbae.org/index.php?option=com_phocadownload\&vie $\mathrm{w}=$ category $\& \mathrm{id}=5$ : writing-the- wrongs $\&$ download $=17$ : writing-thewrongs \&Itemid $=54$.

Baker, D and Street, B (1994) Literacy and Numeracy: Concepts and definitions, in Husén, T and Postlethwaite, T, eds, The International Encyclopedia of Education, 2nd edition, Pergamon Press, Oxford, pp 3453-3459.

Barton, D and Papen, U (2005) Linking Literacy and Numeracy Programmes in Developing Countries and the UK, National Research and Development Centre for Adult Literacy and Numeracy (NRDC), London. 
Central Intelligence Agency (CIA) (2010) The World Factbook, retrieved Dec 302010 from https://www.cia.gov/library/publications/theworld-factbook/geos/nu.html.

Friedman, S.L and Scholnick, E.K (1997) An Evolving 'Blueprint' for Planning: Psychological requirements, task characteristics, and social-cultural influences, in Friedman, S.L and Scholnick, E.K, eds, The Developmental Psychology of Planning, Lawrence Erlbaum Associates, Mahwah, pp 3-22.

Gahamanyi, M (2010) A Study of Mathematical Organisations in Rwandan Workplaces and Educational Settings, Dissertation, Linkoeping University, Linkoeping.

International Labour Organisation (ILO) (2002) Women and Men in the Informal Economy: A statistical picture, ILO, Geneva.

Lave, J (1988) Cognition in Practice: Mind, mathematics and culture in everyday life, Cambridge University Press, Cambridge.

Lekoko, R.N and Garegae, K.G (2006) Intuitive Mathematical Knowledge as an Essential Aspect of Contemporary Adult Learning: A case of women street vendors in the city of Gaborone, Literacy and Numeracy Studies, vol 15, no 1, pp 61-77.

Lindenskov, L and Wedege, T (2001) Numeracy as an Analytical Tool in Mathematics Education and Research, Danish University of Education, Roskilde.

Mayring, P (2008) Qualitative Inhaltsanalyse. Grundlagen und techniken, Beltz, Weinheim.

Naresh, N (2008) Workplace Mathematics of the Bus Conductors in Chennai, India, Dissertation. Illinois State University, Illinois.

Nunes, T, Schliemann, A.D and Carraher, D.W (1993) Street Mathematics and School Mathematics, Cambridge University Press, Cambridge.

Saxe, G.B (1991) Culture and Cognitive Development: Studies in mathematical understanding, Lawrence Erlbaum, Hillsdale.

Sebstad, J and Cohen, M (2003) Financial Education for the Poor, retrieved Jan 262011 from: http://www.globalfinancialed.org/documents/WP1_FinEd4Poor.pdf.

Street, B, Baker, D and Tomlin, A (2008) Navigating Numeracies Home/school numeracy practices, Springer, Dordrecht.

United Nations (2000) United Nations Millennium Declaration, retrieved Jan 62011 from: http://www.un.org/millennium/declaration/ares552e.htm.

Vuletin, G (2008) Measuring the Informal Economy in Latin America and the Caribbean, International Monetary Fund, Washington.

Wedege, T (1999) To Know or Not to Know - Mathematics, that is a question of context. Educational Studies in Mathematics, vol 39, no 1-3, pp 205-227. 
World Education Forum (2000) The Dakar Framework for Action.

Education for all: Meeting our Collective Commitments, UNESCO, Paris.

\section{Endnote}

1 This condition has been changed since the time of the interviews the women no longer have to pay back the money, it has therefore become a donation rather than a credit.

\section{Acknowledgements}

The author would like to express her heartfelt thanks to all those who attentively read and critically commented on various drafts of this article. 